\title{
Who will guard the guards? Medical leadership and conflict of interest in South African healthcare
}

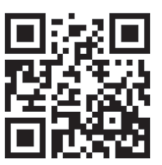

The pharmaceutical industry has filled a vacuum. A few decades ago, medical leaders would set research directions and would lobby for products to treat problems faced by their patients. Today, in an era of disease mongering and priority setting by pharmaceutical firms, leaders often react to industry rather than setting clear priorities in worthwhile diagnostic and therapeutic spend.

Conflict of interest (COI) may cause harm if it influences the quality of patient care, the integrity of research, the objectivity of education, or community trust in healthcare. ${ }^{[1]}$ There is a need for transformational medical leadership ${ }^{[2]}$ that unifies followers, restores professionalism and takes back control of the direction and purpose of medical care.

We aim to raise awareness of COI issues that may have been incompletely explored during medical training, including some tactics used by the pharmaceutical industry to influence thought leaders.

\section{What is COI?}

COI happens if the interests of clinicians do not align with those of their patients. ${ }^{[3]}$ More broadly, it is a condition where professional judgement in a primary interest may be unduly influenced by a secondary interest. It is a set of conditions rather than an established behaviour, ${ }^{[4]}$ in that it identifies potential for harm rather than making a judgement of established wrong-doing. ${ }^{[5]}$ Harm occurs if conditions fostering a conflict in loyalties translate into a biased decision.

COI will always be present when healthcare is practised as a marketable commodity. ${ }^{[6]}$ Healthcare provision differs from other financial transactions in that there is both asymmetry of information and patient vulnerability. Patients struggle to balance benefit and harm, many decisions are urgent, and decisions may have lasting and very personal physical consequences. Patients trust the skill and integrity of clinicians, and this is reflected in societal respect for professional status and clinical autonomy. ${ }^{[7]}$

However, erosion of this trust may be increasing, although changes happening over decades are difficult to measure. In the USA, polls during the last quarter of the 20th century reflect a $20-30 \%$ reduction in public faith in the authority of medicine. ${ }^{[8]}$

\section{Manifestations of COI}

Revelations of conflicts leading to serious patient harms have renewed public interest in managing COI. Many of these revelations arose not so much from directed research but from public disclosures as part of legal proceedings against the pharmaceutical industry. ${ }^{[9]}$ Further stimulus may have been from a flurry of books covering aspects of pharmaceutical company influence ${ }^{[10-12]}$ and a website designed to document some of these influences. ${ }^{[13]}$

\section{Key opinion leaders}

Key opinion leaders (KOLs, 'thought leaders') are identified by the pharmaceutical industry as clinicians who are regularly asked for advice by colleagues, often speak at conferences, have a good publication record, consider themselves early adopters of new treatments, and assist in guideline development. ${ }^{[14]}$ There is an 'influence cascade' of KOLs, starting with an international panel of advisory board members brought together strategically early in the product development cycle. These link to national and then local KOLs, with the performance and market worth of the latter being assessed by influence on prescription numbers. ${ }^{[15]} \mathrm{KOLs}$ are nurtured by pharmaceutical manufacturers, with a sub-industry devoted to their selection, as stated on one website: 'With centers of excellence assessments we take a drill-down approach, starting at the academic medical centers, then moving into affiliated hospitals and clinics, and, finally, providing identification and in-depth analysis of significant affiliated physicians in educational and clinical roles.'[16]

Some companies have developed software to aid in thought-leader selection, and also use social network analysis. ${ }^{[17]}$ KOLs influence practice, with a Cochrane review finding that they contributed to a $12 \%$ overall improvement in compliance with clinical practice guidelines. ${ }^{[18]}$

\section{Gifting}

Clinicians generally do not think that small gifts influence their own behaviour, but are less charitable about the effect on their colleagues. A study in 2001 revealed that $61 \%$ of doctors thought they would not be influenced personally, but the same individuals thought that only $16 \%$ of their colleagues would remain uninfluenced. ${ }^{[19]}$ Even small gifts have an effect - raters who denied conscious awareness of influence scored artwork higher if accompanied by the logo of the group subsidising their participation in the trial, and accompanying magnetic resonance images showed clear evidence of increased venteromedial prefrontal cortex activity (an area considered to influence preference judgements). ${ }^{[20]}$

\section{Ghost writing}

This happens when an individual writes a portion of a manuscript but is not listed as an author or contributor. Ghost writing is an industry in its own right, ${ }^{[21]}$ and writers may be contracted by the pharmaceutical industry to prepare a manuscript for publication as part of a process organised by 'publication planners' employed by medical education and communication companies. Such articles may then be gifted to KOLs to 'assist' with final editing. ${ }^{[2]}$

A study comparing protocols approved by the Scientific-Ethical Committee for Copenhagen and Frederiksberg with the corresponding publications of industry-initiated trials found evidence of ghost authorship in $75 \%$ (95\% confidence interval (CI) 60 - 87\%). ${ }^{[23]}$

\section{Impact of COI}

Evidence of the impact of marketing on patient-level outcomes is still scanty, but it does influence prescribing and doctors' attitudes. ${ }^{[24]}$ There is clear evidence that the position of opinion leaders may correlate with industry affiliation. A recent systematic review of positions taken on the safety of rosiglitazone in the wake of reports questioning its cardiovascular harms found a rate ratio of 3.36 (95\% CI 1.94 - 5.83) in support of the agent in those with financial COI compared with those without. Nearly a quarter of these articles with authors with COI did not disclose this, with 3.3\% actively declaring no COI when one did in fact exist. ${ }^{[25]}$

\section{Interventions for dealing with $\mathrm{COI}$ Disclosure}

Much of the information on the effect of disclosure is derived from social science experiments on university student volunteers. 
There is little work on clinicians. What evidence there is suggests that declaration does exactly the opposite of what is intended, and enhances the effect of bias. Reasons for this include insinuation anxiety ('burden of disclosure' - if you don't take the advice of somebody who has declared a potential COI, it is impolite because it implies that you believe that such conflict really exists), inadequate discounting ${ }^{[26]}$ by recipients of the COI information with no independent measure of truth, moral licensing ('I have told you I am biased, now I can really exaggerate to compensate for your expected reaction' - i.e. 'strategic exaggeration'), and the panhandler effect ${ }^{[27]}$ ('Now that I have told you about my financial interests, don't you feel obliged to help me make a bit of money here?').

The 2010 US Physician Payments Sunshine Act requires that payers report any payment of more than $\$ 10$, including meals, entertainment, consultancy fees, speaker payments, research grants and stock options. This Act was implemented in 2013, but earlier reports of disclosure are somewhat disheartening - for example, one study looking at clinicians receiving more than $\$ 100000$ per annum from industry found that nearly a quarter of their publications failed to declare this conflict. ${ }^{[28]}$

\section{Creating awareness}

In the face of evidence that self-awareness of conflict is usually inadequate, a structured non-punitive and nationally consistent approach to recognising and handling COI should be seen as integral to both undergraduate and postgraduate medical education.

\section{Academic counter-detailing}

Although this has statutory funding in both the USA and Canada, there is as yet little evidence that it can compete against the marketing might of the industry in its own right. A change in mindset might be helpful. If, for instance, in all local conferences there was a unanimous and consistent call for evidence-based and unconflicted debate, this might allow a culture of true academic review to be reborn.

\section{Fostering professionalism}

This has evolved from being seen as an innate characteristic to being measurable as a series of observable behaviours - being 'in service' to patients, demonstrating integrity and accountability, pursuing clinical excellence, and practising fair and ethical stewardship of healthcare resources. ${ }^{[29]}$ This approach disaggregates professionalism into separate competencies that clinicians should continue to develop over time and includes a specific recommendation that potential conflicts of interest should be actively managed.

\section{Conclusion}

In the absence of good leadership, we will remain in perpetual conflict between the aim of best serving our patients and the desire to remain funded by a profit-driven industry. Clinicians who recognise and manage conflict of interest are better equipped to lead the profession on a more impartial and patient-centred course. Colleagues, funders and patients should feel confident that decision makers and opinion leaders make evidence-based decisions without pecuniary or other conflicts.

\section{Andy Parrish}

Department of Internal Medicine, Frere and Cecilia Makiwane

hospitals, East London, Eastern Cape, South Africa

Marc Blockman

Department of Internal Medicine, Division of Clinical Pharmacology, Faculty of Health Sciences, Groote Schuur Hospital and

University of Cape Town, South Africa

Corresponding author: A Parrish (andygp@mweb.co.za)

1. Lo B, Field MJ. Conflict of Interest in Medical Research, Education, and Practice. National Academies Press, 2009. http://www.nap.edu/catalog.php?record_id=12598 (accessed 30 May 2014).

2. Aarons GA. Transformational and transactional leadership: Association with attitudes toward evidence-based practice. Psychiatr Serv 2006;56(8):1162-1169. [http://dx.doi.org/10.1176/appi.

ps.57.8.1162]
Tonelli MR. Conflict of interest in clinical practice. Chest 2007;132(2):664-670. [http://dx.doi. org/10.1378/chest.07-0315]

Thompson DF. Understanding financial conflicts of interest. N Engl J Med 1993;329(8):573-576. [http://dx.doi.org/10.1056/NEJM199308193290812]

5. Smith R. Conflicts of interest: How money clouds objectivity. J Royal Soc Med 2006;99(6):292-297. [http://dx.doi.org/10.1258/jrsm.99.6.292]

6. Nguyen $\mathrm{H}$. The principal-agent problems in health care: Evidence from prescribing patterns of private providers in Vietnam. Health Policy Plan 2011;26(Suppl 1):53-i62. [http:///x.doi.org/10.1093/heapol/czro28] 7. Clark CC. Trust in medicine. J Med Philos 2002;27(1):11-29. [http://dx.doi.org/10.1076/ jmep.27.1.11.2975]

8. Schlesinger M. A loss of faith: The sources of reduced political legitimacy for the American medical profession. Milbank Q 2002;80(2):185-235. [http://dx.doi.org/10.1111/1468-0009.t01-1-00010]

9. Steinman MA, Bero LA, Chren MM, Landefeld CS. Narrative Review: The promotion of gabapentin An analysis of internal industry documents. Ann Intern Med 2006;145(2):284-293. [http://dx.doi. org/10.7326/0003-4819-145-4-200608150-00008]

10. Angell M. The Truth About the Drug Companies: How They Deceive Us and What To Do About It. New York: Random House, 2004.

11. Kassirer JP. On the Take: How Medicine’s Complicity With Big Business Can Endanger Your Health. Oxford: Oxford University Press, 2005

12. Goldacre B. Bad Pharma: How Medicine Is Broken and How We Can Fix It. London: Harper Collins, 2013.

13. ProPublica. Dollars for Docs: How Industry Dollars Reach Your Doctors. http://projects.propublica. org/docdollars/ (accessed 30 May 2014).

4. PR Web. What makes a key opinion leader a KOL? http://www.prweb.com/releases/2012/3/ prweb9250355.htm (accessed 26 March 2014).

15. Sismondo S. Corporate disguises in medical science: Dodging the interest repertoire. Bull Sci Technol Soc 2011;31(6):482-492. [http://dx.doi.org/10.1177/0270467611422838]

16. Thought Leader Select. http://www.thoughtleaderselect.com (accessed 30 May 2014).

17. KOL, L.L.C. The key to opinion leader development. http://www.kolonline.co (accessed 30 May 2014).

18. Flodgren G, Parmelli E, Doumit G, et al. Local opinion leaders: Effects on professional practice and health care outcomes. Cochrane Database Syst Rev 2011;8:CD000125. [http://dx.doi. org/10.1002/14651858.CD000125.pub4]

19. Steinman MA, Shlipak MG, McPhee SJ. Of principles and pens: Attitudes of medicine housestaff towards pharmaceutical industry promotions. Am J Med 2001;110(7):551-557. [http://dx.doi. org/10.1016/S0002-9343(01)00660-X]

20. Harvey AH, Kirk U, Denfield GH, Montague PR. Monetary favours and their influence on neural responses and revealed preference. J Neuroscience 2010;30(28):9597-9602. [http://dx.doi.org/10.1523/ JNEUROSCI.1086-10.2010]

21. Sismondo S. Ghost management: How much of the medical literature is shaped behind the scenes by the pharmaceutical industry? PLoS Med 2007;4(9):e286. [http://dx.doi.org/10.1371/journal. pmed.0040286]

22. Berenson A Evidence in Vioxx suits shows intervention by Merck officials. New York Times, 24 April 2005. http://www.nytimes.com/2005/04/24/business/24drug.html (accessed 26 March 2014).

23. Gøtzsche PC, Hrobjartsson A, Johansen HK, et al. Ghost authorship in industry-initiated randomised trials. PLoS Med 2007;4(1):e19. [http://dx.doi.org/10.1371/journal.pmed.0040019]

24. Wazana A. Physicians and the pharmaceutical industry. Is a gift ever just a gift? JAMA 2000;283(3):373380. [http://dx.doi.org/10.1001/jama.283.3.373]

25. Wang AT, McCoy CP, Murad MH, Montori VM. Association between industry affiliation and position on cardiovascular risk with rosiglitazone: Cross sectional systematic review. BMJ 2010;340:c1344. [http://dx.doi.org/10.1136/bmj.c1344]

26. Daylian M, Loewenstein G, Moore DA. The dirt on coming clean: Perverse effects of disclosing conflicts of interest. J Legal Stud 2005:34(1):1-25. [http://dx.doi.org/10.1086/426699]

27. Sah S, Loewenstein G, Cain DM. The burden of disclosure: Increased compliance with distrusted advice. J Personality Soc Psychol 2013;104(2):289-304. [http://dx.doi.org/10.1037/a0030527]

28. Norris SL, Holmer HK, Ogden LA, Burda BU, Fu R. Characteristics of physicians receiving large parris SL, Holmer HK, Ogden LA, Burda BU, Fu R. Characteristics of physicians receiving large
payments from pharmaceutical companies and the accuracy of their disclosures in publications: An observational study. BMC Med Ethics 2012;13:24. [http://dx.doi.org/10.1186/1472-6939-13-24]

29. Lesser CS, Lucey CR, Egener B, Braddock CH, Linas SL, Levinson W. A behavioural and systems view
of professionalism. JAMA 2010;304(24):2732-2737. [http://dx.doi.org/10.1001/jama.2010.1864]

S Afr Med J 2014;104(11):757-758. DOI:10.7196/SAMJ.8546 